\title{
POR ENTRE PAPEIS E FIOS SOLTOS: CONTRIBUIÇÕES PARA A ESCRITA DA HISTÓRIA DA EDUCAÇÃO A PARTIR DOS ARQUIVOS DA ESCOLA TÉCNICA ESTADUAL HENRIQUE LAGE
}

\section{IN BETWEEN ROLES AND LOOSE THREADS: CONTRIBUTIONS FOR WRITING HISTORY OF EDUCATION FROM THE FILES SCHOOL STATE TECHNICAL HENRIQUE LAGE}

\author{
Sônia Camara* \\ Sâmela Cristinne Carvalho Ignácio** \\ Janilce Aparecida Conceição Magalhães ${ }^{* * *}$
}

Resumo: O presente artigo objetiva apresentar os primeiros esforços constituídos pelas equipes de pesquisadores da Universidade do Estado do Rio de Janeiro e do Centro de Memória da Escola Técnica Estadual Henrique Lage, no sentido de, por um lado, organizar ações de identificação, sistematização e preservação dos acervos documentais existentes na escola e, por outro inquerir e problematizar os documentos quanto as dinâmicas e fazeres instituídos na escola. Para este intento, estabelecemos como recorte temporal os anos de 1923 a 1930, por considerá-lo fecundo para a compreensão do projeto de profissionalização instituído na escola que, criada em 1923, teve sua história tingida pelos ideais de renovação da educação advindos com o movimento da Escola Nova. A partir dos papéis e dos fios soltos localizados nos arquivos da escola, objetivamos tramar uma tessitura que faça emergir "outras histórias" acerca da instituição.

Palavras-chave: Arquivo Escolar. Prática Escolar. Ensino Profissional.

\footnotetext{
* Professora do Programa de Pós-Graduação em Educação (ProPEd) e do Programa de Pós-Graduação Processos Formativos e Desigualdades Sociais e coordenadora do Laboratório Interdisciplinar de Estudos e Pesquisas em História da Educação e Infância da Universidade do Estado do Rio de Janeiro (UERJ). Procientista UERJ/FAPERJ. Email: soniacamara@uol.com.br.

** Pedagoga (FFP/UERJ), Especialista em Educação Básica (FFP/UERJ) e Psicopedagogia (ISAT). Mestre em Educação pela Universidade Federal do Estado do Rio de Janeiro (Unirio). Supervisora Educacional da Escola Técnica Estadual Henrique Lage pertencente à Fundação de Apoio à Escola Técnica do Rio de Janeiro (FAETEC). Pesquisadora do Centro de Memória Henrique Lage. Orientadora Educacional do Município de São Gonçalo.. Email: samelacristine@yahoo.com.br.

*** Bibliotecária formada pela Universidade Federal Fluminense (UFF). Bibliotecária da Escola Técnica Estadual Henrique Lage pertencente à Fundação de Apoio à Escola Técnica do Rio de Janeiro (FAETEC). Email: janilcemagalhaes@yahoo.com.br.
} 


\begin{abstract}
This article aims to present the first efforts made by the teams of researchers from the State University of Rio de Janeiro and the Memory Center of the Henrique Lage State Technical School, in order to organize actions to identify, systematize and preserve Collection of documents in the school and, on the other hand, inquiring and problematizing the documents about the dynamics and practices instituted in the school. For this purpose, we established as a temporal cut from the years 1923 to 1930 , considering it fruitful for the understanding of the project of professionalization instituted in the school that, created in 1923, had its history tinged by the ideals of education renewal coming from the movement Of the New School. From the loose papers and wires located in the archives of the school, we aim to create a framework that will bring forth "other stories" about the institution.
\end{abstract}

Keywords: School file. School practice. Professional education.

\title{
Introdução
}

A educação da juventude como base da ordem social é um momentoso problema que está a desafiar a todos quanto se empenham pelo futuro do Brasil, ameaçado por ideias subversivas e pelas paixões das que deviam patrioticamente sacrificar as suas ambições, pondo acima de tudo o bemestar da família brasileira.

Não há quem conteste, ao menos de boa fé, a necessidade de proporcionar a escola moderna um ambiente mais vasto do que o atual, pois sendo o homem um produto do meio em que se forma, é claro que precisamos de melhorar este meio, dando à escola um caráter educativo, desde que é sob o seu teto que estão preparando as novas gerações, afim de que estas se tornem capazes das grandes realizações em proveito de um Brasil melhor (O JORNAL, 17/06/1928).

No contexto da década de 1920, a urbanização, a industrialização e a educação foram tomadas como paradigmas de progresso e de modernização, mobilizando a construção de projetos e programas de intervenção sobre a sociedade vista, pelos reformadores sociais, como amorfa e atrasada. Neste cenário, a educação foi concebida simultaneamente como problema e como "chave" capaz de resolver os problemas sociais que afligiam o Brasil. Associada à esta visão, assumiu centralidade, para os intelectuais educadores $^{1}$ envolvidos com a implementação dos pressupostos advindos com a Escola Ativa (Escola Nova), a concepção de que a educação deveria se reorganizar a partir do que seria uma nova finalidade pedagógica e social, sendo as escolas concebidas como um "elemento dinâmico, criador e disciplinador de energias" às novas gerações (PROGRAMA PARA OS JARDINS DE INFÂNCIA E ESCOLAS PRIMÁRIAS, 1929, p. 6).

Nesta direção, com matéria intitulada Aspectos da moderna pedagogia, o periódico

\footnotetext{
${ }^{1}$ Estaremos trabalhando com a acepção de intelectuais educadores para definir os homens e mulheres que oriundos de diferentes campos de formação, engajaram-se em torno da crença no papel transformador da educação. Estes se autodenominavam reformadores sociais.
} 
O Jornal de 17 de junho de 1928 procurou evidenciar a proposta de que a "escola moderna" deveria funcionar como um "ambiente mais vasto" em "proveito de um Brasil melhor". Assim, caberia à escola atuar como instituição capaz de suplantar as deficiências do povo brasileiro - analfabetismo, doença, indolência - colaborando na construção de valores que se irradiassem às famílias e ao meio social de onde as crianças provinham.

Com isso, medidas foram concebidas e implementadas, pelos intelectuais educadores, visando preceituar, orientar e organizar às escolas a partir de uma nova finalidade educativa, redentora e moralizante. Para isto, a escola foi pensada como estratégia de intervenção social, como espaço-lugar de transformações envolvendo as suas práticas e os seus fazeres. Ênfase foi atribuída à máxima de que era preciso "fazer trabalhar para aprender (ensinar pelo trabalho), ensinar a trabalhar", despertando o hábito e a "técnica geral do trabalho" (PROGRAMA PARA OS JARDINS DE INFÂNCIA E ESCOLAS PRIMÁRIAS, 1929, p. 8).

A emergência do trabalho livre e produtivo, a partir de finais do século XIX, trouxe implicações sobre a forma de organização da sociedade e da educação intensificando, especialmente, a partir dos movimentos reformistas da educação, a necessidade de se estabelecer debates acerca da organização social e do mundo do trabalho. O ideário civilizador corporificado na lógica do tempo controlado e racional da indústria, dos ponteiros do relógio passou a marcar o ritmo da vida e das relações sociais dos diferentes setores da sociedade. As reformas da instrução pública concebidas pelos intelectuais em vários estados da Federação, visavam ajustar “[...] os homens às novas condições e valores de vida". Este movimento implicou em "promover mudanças de mentalidade no trato das questões educacionais, envolvendo estratégias de opinião pública" (CARVALHO, 2011, p. 233).

Desta forma, embora a educação tenha sido apresentada como elemento de redenção do País ao progresso e à modernização, ela não esteve imune às críticas quanto à sua organização. Para Camara (2013), exemplar foram as apreciações e críticas formuladas pelo educador e diretor da Instrução Pública do Distrito Federal, Fernando de Azevedo (1927-1930), que ao tratar a educação profissional, afirmava ser a "mentalidade bacharelesca e doutoral" um dos graves problemas a ser suplantado em bem da Nação. Assim, afirma Camara que na concepção de Azevedo essa "mentalidade":

[...] criou uma visão de ojeriza às atividades manuais, que não eram vistas 
como profissões, mas sim como ofícios. No Brasil, onde o processo de formação das cidades se desenvolveu sob a influência da aristocracia rural e, só então, começava a industrializar-se. Neste contexto as funções liberais como advocacia, medicina, funcionalismo e milícia preponderavam sobre as funções usuais como agricultura, industria e comércio (CAMARA, 2013, p. 149-150).

À crítica formulada, decorrentes desta compreensão, pretendia atacar este problema, por meio do primado da educação assente na valorização das atividades manuais e no trabalho produtivo, articulando, assim, o ensino profissional às necessidades do País. Esta compreensão, acerca da importância do ensino profissional, impulsionou iniciativas voltadas à criação de escolas profissionais, consubstanciadas pela prerrogativa de que era preciso educar a infância pobre pelo trabalho e para o trabalho produtivo.

Nesta direção, a criação da Escola Profissional Washington Luís, em Niterói, capital do Estado do Rio de Janeiro, na década de 1920, será compreendida, por nós, como parte das estratégias de intervenção empreendidas no sentido de se instituir a promoção de espaços de educação profissional para as crianças pobres. A perspectiva profissional assumida pela instituição relacionava-se a tentativa de se atender as aspirações políticas e sociais que a questão da modernização e do trabalho geravam à época. Portanto, ao longo de seus noventa e quatro anos, a instituição tem se constituindo como um importante espaço de formação e de experimentação de práticas pedagógicas no contexto das instituições de ensino profissionalizante e técnico da região. Desta trajetória institucional construída, muitos objetos, documentos e fotografias permaneceram na escola como marcas, vestígios instituídos a partir das políticas públicas que se materializaram no âmbito da educação profissional no Estado do Rio de Janeiro.

Visando promover ações direcionadas à preservação das fontes documentais existentes na escola, bem como colaborar para a realização de um esforço reflexivo acerca da escrita da história da educação, este artigo tem como intuito apresentar as iniciativas de pesquisa empreendidas pelas equipes de pesquisadores do Núcleo Interdisciplinar de Pesquisa em História da Educação e Infância (NIPHEI) da Universidade do Estado do Rio de Janeiro (UERJ) e do Centro de Memória da Escola Técnica Estadual Henrique Lage (CMHL), pertencente à Fundação de Apoia à Escola Técnica do Rio de Janeiro (FAETEC), envolvidas com a realização do projeto de pesquisa e extensão "História, memória e preservação documental: contribuição para a história da educação profissional a partir dos arquivos 
escolares da Escola Henrique Lage". 2

Nesta perspectiva, o artigo se estrutura em dois momentos complementares: no primeiro, apresenta os aspectos que têm mobilizado a implantação de ações de identificação, sistematização e preservação dos acervos documentais existentes na escola, refletindo sobre sua relevância para a história da educação; no segundo, objetiva de forma preliminar analisar as fontes documentais que, sistematizadas e interpretadas pelos pesquisadores envolvidos na pesquisa, permitam adensar assertivas acerca das práticas escolares, dos fazeres ordinários instituídos e do perfil dos sujeitos escolares atendidos na instituição nos primeiros anos de sua existência, de 1923 a 1930.

Consideramos que a possibilidade de recuperação e democratização das informações, advindas com este trabalho, deve considerar o princípio de respeito aos fundos, que é o conjunto de documentos de uma mesma proveniência (BELLOTO,1984) e, desta forma, contribuir para a reflexão crítica acerca das políticas de preservação, recolhimento e guarda de acervos documentais existentes em instituições escolares que se encontram em risco de perda, bem como para a maior sensibilização, junto a um público mais amplo quanto a importância das fontes documentais produzidas nas escolas.

\section{Identificação, sistematização e preservação de fontes: primeiras aproximações}

Aventurar-se pelos arquivos, portanto, é sempre um desafio de trabalhar em instalações precárias, com documentos mal acondicionados e preservados, e mal organizados. Portanto, o historiador tem sempre pela frente o desafio de permanecer por meses, quando não por anos, nesses ambientes pouco acolhedores em termos de conforto e de condições de trabalho, mas em um esforço que quase sempre levará a alcançar resultados muito gratificantes (BACELLAR, 2014, p. 49).

A constituição de um esforço inicial no sentido de nos aventurarmos pelos espaços da escola em busca de registros documentais e objetos relativos à história da escola foram

\footnotetext{
${ }^{2} \mathrm{O}$ projeto se organiza em três direções: a primeira refere-se ao esforço de colaborar com a identificação, organização e divulgação dos acervos da escola, objetivando promover a socialização de informações acerca das fontes de arquivo, coleções, material hemerográfico e peças de museu para a realização de estudos e pesquisas no âmbito da História da Educação profissional fluminense; a segunda direciona-se a organização dos documentos e objetos existentes na escola a fim de produzir materiais (escritos e multimídia) para uso no ensino; a terceira relaciona-se a preocupação em socializar discussões sobre a importância da preservação da memória da instituição e da história da instituição junto a professores, alunos e pesquisadores interessados em pensar sobre a educação e a escolarização no município de Niterói e no Estado do Rio de Janeiro no que tange a formação profissional e técnica.
} 
impactantes. Entre as dificuldades que foram se apresentando, tínhamos um desafio maior a enfrentar: a sala do arquivo "morto" da escola. A sala era um dos principais espaços em que foi possível identificar uma parte expressiva de documentos referentes à escola, desde sua criação até os dias atuais. $O$ arquivo da Escola Técnica Estadual Henrique Lage acumula documentos relativos a noventa e quatro anos de história que se encontravam sem acondicionamento, organização e limpeza adequada. A sala em que se localiza o arquivo da escola possui cerca de vinte metros quadrados, em que são dispostos setenta e quatro arquivos de aço que não se encontram em condições muito favoráveis para o manuseio e acondicionamento dos documentos, além de seis armários, nos quais foi possível encontrar diferentes tipos de documentos que necessitavam ser identificados, separados, higienizados, acondicionados e organizados a partir dos critérios das três idades dos arquivos. Nesta direção, segundo Bonato, os arquivos se organizam em:

Arquivo Corrente ou de primeira idade, constituído de documentos em curso e consultados frequentemente. De natureza administrativa, atendem às necessidades imediatas para as quais foram produzidos e por isso se conservam junto aos órgãos produtores; arquivo intermediário ou de segunda idade, nos quais os documentos não são mais consultados tão frequentemente, porém, ainda, podem ser solicitados para retomada de alguma questão pelo órgão que os produziu. Já foram avaliados e aguardam destinação final de acordo com a Tabela de Temporalidade dos Documentos; arquivo permanente ou de terceira idade, constituído de documentos que perderam todo o valor de natureza administrativa, mas que se conservam definitivamente em razão de seu valor histórico ou probatório, de acordo com a avaliação documental (2000, p. 47).

A par desta compreensão, entendemos que a realização da pesquisa se organiza tendo em mira a intenção de potencializar discussões e iniciativas acerca da seleção, preservação e acesso às fontes documentais produzidas pelas instituições escolares. Desta forma, esperamos colaborar para um debate mais amplo acerca da natureza, arranjo, guarda e socialização dos materiais e sua informação pelas instituições detentoras de documentos de valor histórico. A ampliação da noção de documento como "testemunho histórico" e, portanto, como recurso "indispensável" à história tem mobilizado iniciativas no sentido de se promover esforços direcionados à guarda de materiais que possam colaborar para a apreensão e compreensão do passado.

Assim, como nos adverte Le Goff (1990, p. 541), a "revolução documental” que se operou trouxe para à cena novos objetos e problemas ampliando, desta forma, a noção de 
documento e a compreensão de que o dado não existe à priore, é sempre uma construção que depende do olhar do historiador. Ponderando acerca do documento, Febvre (apud LE GOFF, 1990, p. 540), afirma que: "a história faz-se com documento escritos, sem dúvida. Quando estes existem. Mas pode fazer-se, deve fazer-se sem documentos escritos, quando não existem. Com tudo o que a habilidade do historiador lhe permite utilizar para fabricar o seu mel, na falta das flores habituais". O trabalho de organização dos fundos da Escola Técnica Estadual Henrique Lage orienta-se pelo desejo de se construir séries documentais a partir das quais os pesquisadores, mobilizados por questões-problema, visam enredar análises acerca da história da instituição, das práticas e dos fazeres ordinários envolvendo a história da educação profissional no Estado do Rio de Janeiro.

Idealizado a partir de 2012, o Centro de Memória Henrique Lage ${ }^{3}$, se associa as iniciativas realizadas por pesquisadores no âmbito da História da Educação brasileira, a partir da década de 1990, no sentido de incorporar não somente os documentos oficiais em circulação nas escolas, mas também os cadernos, os desenhos, os livros, os cadernos de recordação, as fotografias, as fichas de alunos, os diários de classe, o prédio escolar como fontes significativas para a escrita da história da educação. A criação do Centro de Memória e a parceria instituída com a Universidade do Estado do Rio de Janeiro têm potencializado a realização de ações visando consolidar metodologias de trabalho envolvendo a identificação, sistematização e organização dos documentos que colaboram para a construção de uma história da instituição, dos sujeitos que a constituíram, das políticas e dos projetos de educação elaborados pelo Estado no âmbito da educação profissional. Entre as metas definidas para o Centro de Memória, estabelece-se que:

O setor tem como meta a formulação e execução de uma política institucional que promove a cultura de preservação do patrimônio escolar e possibilita a salvaguarda de documentos que compõem os diversos acervos encontrados e organizados no Centro de Memória da Fundação e das unidades escolares. Dessa forma, considerando a importância da política de valorização e reconhecimento da história, a FAETEC, através do Centro de Memória, estabelece ações institucionais que garantem a preservação das fontes e arquivos escolares, possibilitando a recuperação da sua memória institucional e incentivando a pesquisa sobre a educação profissional (Site da FAETEC).

\footnotetext{
${ }^{3}$ O Centro foi institucionalizado a partir da portaria Faetec $n^{\circ} 101$ de 15 de maio de 2002 e publicado no Diário Oficial do Estado do Rio de Janeiro em 24 de maio de 2002.
} 
É sabido que tudo no mundo é perecível, e em se tratando da documentação a degradação geralmente tende a ser mais incisiva devido às mudanças climáticas e os diversos agentes que compõem o meio ambiente como roedores, traças, brocas, cupins entre outros que atacam desde documentos em papel, fotografias até mesmo fitas de vídeo e o mobiliário. Estes fatores são indicativos da necessidade de se realizar ações destinadas a promover a preservação dos documentos em qualquer instituição e, em particular em instituições escolares em que as dinâmicas cotidianas envolvendo as questões diárias do tempo presente acabam assumindo maior centralidade em detrimento das demandas envolvendo o passado e os vestígios que povoam os espaços escolares. Vistos em sua materialidade como parte do "arquivo morto" das instituições, os documentos, vestígios do passado, passam a compor o depósito de "velharias" das escolas, quando não são descartados por serem considerados sem importância e significação para as demandas diária das escolas. Em geral, o processo de descarte acaba sendo realizado sem que sejam observados critérios mínimos que orientem o procedimento. A par desta compreensão, Bonato, (2000) sinaliza sobre a importância dos arquivos escolares no que concerne à História da Educação, na qual,

$\mathrm{O}$ arquivo de uma escola tem por finalidade armazenar a documentação de interesse da escola que venha auxiliar a administração e o ensino, assim como permitir o levantamento de dados para pesquisa educacional e histórica da instituição e da comunidade na qual ela está inserida. [...]. Esse tipo de acervo arquivístico representa um patrimônio documental, que integra a memória da instituição escolar que o gera e é parte da memória educacional brasileira (BONATO, 2000, p. 45).

Desta forma, a partir do trabalho que vem sendo realizado por pesquisadores preocupados com as dinâmicas de produção documental das escolas, bem como dos materiais didáticos utilizados por elas, a exemplo dos livros, mapas, projetores e, outros equipamentos que passaram a constituir-se como fontes significativas para a promoção de pesquisas no âmbito da história da educação brasileira. Os trabalhos de identificação de fontes documentais, imagéticas e tridimensionais na escola tem potencializado promovermos estudos que se organizam no sentido de constituir a compreensão acerca dos fazeres ordinários e da cultura escolar. Nesta direção, o trabalho tem tencionado localizar, identificar e sistematizar os vestígios do passado transformando-os em documentos e, a partir deste movimento, realizar a sua indexação a partir de uma metodologia de trabalho 
que envolve o uso de fichas de pesquisa, elaborada pela equipe de pesquisadores, com o intuito de sistematizar os dados relativos as fontes documentais localizadas na escola. ${ }^{4}$

Nesta perspectiva, as fontes assumem importância pela possibilidade que trazem de potencializar interrogações sobre o funcionamento cotidiano da escola, mas também das apropriações e relações que se organizaram a partir das legislações e normativas que visavam regular o seu funcionamento, bem como os fazeres dos professores e alunos. Com um acervo documental constituído por uma quantidade expressiva de dossiês de alunos, centenas de fotografias avulsas e álbuns fotográficos, o Centro de Memória e o NIPHEI, tem procurado instituir ações voltadas para a sensibilização de alunos e professores quanto a importância da documentação, dos objetos existentes na escola e das trajetórias dos professores e alunos para a história da instituição, do local e da educação. Desta forma, o valor da documentação para o entendimento da história da educação alicerça-se na importância dos arquivos escolares na construção de "outras histórias" até então silenciadas, mas também no "resgate" da memória institucional como aponta Caixeta e Cunha (2013), enquanto possibilidade de se apreender elementos relacionados à história institucional e aos aspectos significativos de construção de sua identidade. Assim:

Nas últimas décadas, o olhar volta-se para o passado, as instituições são tomadas como fatos históricos, e como tais, inseparáveis das circunstâncias que tornaram possíveis sua criação e existência. É importante destacar essa mobilização das próprias instituições em compreender sua história e construir sua identidade, conscientizando-se de seu passado e refletindo acerca de sua memória e tradição (CAIXETA; CUNHA, 2013, s/p).

A fim de compreender a historicidade da escola, a equipe de pesquisadores envolvida com o projeto optou por reunir, nessa primeira fase da pesquisa, os documentos relativos a primeira década de existência da Instituição (1923 a 1930) denominada de Escola Profissional Washington Luís, identificando, separando, limpando, higienizando e acondicionando os documentos para posterior sistematização e digitalização dos acervos. Incorporando ao trabalho com as fontes documentais à preocupação com a memória constituída pelos atores sociais, participantes da instituição, iniciamos investimentos no âmbito da história oral através de entrevistas com ex-alunos, professores, diretores e

\footnotetext{
${ }^{4}$ As fichas vêm sendo aplicadas pelos bolsistas incluídos nos programas de Jovens Talentos da FAPERJ e Extensão da UERJ, envolvidos com o projeto. Para isto, temos procurado instituir uma organização para o fundo no sentido de compor as tipologias documentais. Até o momento já foram identificados: materiais didáticos, máquinas utilizadas nas oficinas da escola, documentos escritos e fotográficos, entre outros.
} 
funcionários.

De acordo com Polack "a memória, a alteridade e a mudança são essenciais na percepção de si e dos outros" (1992, p. 200-212). Nesta direção, o registro das memórias produzidas a partir da percepção construída por esses diferentes atores pode colaborar de maneira expressiva para captar aspectos significativos acerca da história da instituição e desses atores sociais. Ponderando acerca da história oral no conjunto das discussões relativas ao trabalho do pesquisador com as fontes, Alberti afirma que:

Uma entrevista de história oral não é exceção nesse conjunto. Mas há nela uma vivacidade, um tom especial característica de documentos pessoais. É da experiência de um sujeito que se trata; sua narrativa acaba colorindo o passado com um valor que nos é caro: aquele que faz do homem um indivíduo único e singular em nossa história, um sujeito que efetivamente viveu - e, por isso dá vida a outra versão da vida - conjunturas e estruturas que de outro modo parecem tão distantes (ALBERTI, 2004, p.14).

Partindo da compreensão, sinalizada por Alberti (2004), de que as narrativas podem colorir o passado permitindo a produção de interpretações acerca dele, a equipe de pesquisadores envolvidos com o projeto na escola tem enredado esforços no sentido de registrar as diferentes versões constituídas pelos sujeitos que participaram e viveram experiências singulares e coletivas no espaço da escola ao longo de sua história. Nesta perspectiva, vem sendo realizado um trabalho de localização de ex-alunos, professores e funcionários que possam ser entrevistados.

A realização de entrevistas com ex-alunos da escola tem permitido recolhermos informações que não constavam nos documentos textuais existentes no arquivo da instituição. Um fato demonstrativo disto foi a entrevista realizada com o ex-aluno da década de 1920 e ex-professor da escola, Luís Antônio Pimentel, falecido no ano de 2015, aos 103 anos de idade. Conforme entrevista gravada, existente em nosso acervo, o depoente informou que algumas escolas profissionais teriam sido criadas na década de 1920, a partir dos espaços ocupados, bem como dos materiais deixados pelos países que participaram da Exposição Universal ocorrida na cidade do Rio de Janeiro, de 7 de setembro de 1922 a abril de 1923 em comemoração ao Centenário da Independência do Brasil. Afirmou que:

[...] terminada a exposição do Centenário da Independência que ocupou toda a área da praça XV pegando o antigo mercado de peixe, parte de navegação, oficina náutica, quando eles pegaram esta coisa, acabaram se destacando naturalmente aos olhos dos expositores de indústria e de escola profissional, estrangeiro todos eles, se destacou tantos de tal forma que os expositores que 
tinham os galpões enormes, como se fossem hangares de avião, que não havia avião, aqueles divididos para fazer exposição dos países. Então esses expositores que ficaram encantados com o que viram aqui, não tendo o que fazer com esses galpões, combinaram entre eles de doar os galpões para que fizessem uma rede de escolas profissionais, eram muitos países. Tanto assim que nessa época coube ao Brasil ganhar de graça, por simpatia, uma instalação grande para fazer uma escola profissional, como a Washington Luís, ganhar uma área que pertenceu a uma exposição de um país europeu que expos indústria de pesca, a Noruega. Nesse galpão foi instalada a escola profissional Washington Luís, então ele ganhou a escola já com o nome dele. Surgindo escola profissional que não havia (PIMENTEL, 16/05/2014, grifos nossos).

Fato, posteriormente, encontrado em jornais da época, localizados em pesquisa na hemeroteca da Biblioteca Nacional acerca da criação da Escola. Nesta direção, afirmava o jornal $O$ Malho que:

[...] depois de adquirido o Pavilhão da Dinamarca, pensara em transformá-lo numa escola de agricultura e depois num grupo escolar. Mas por razões múltiplas levaram S. Ex. [Feliciano Sodré] a optar por uma escola profissional. S. Ex. acha que houve algo de providencial nessa transmutação. Recorda que por muitas vezes na sua vida, tem estado em contacto com o elemento operário e tem sobejos motivos para acreditar que conta grande número de amigos nessa classe, pois embora muitas vezes mantenedor da ordem, tem sabido respeitar os nobres ideais por que se batem os operários. [...]. Conclui convidando os profissionais que se formarem naquela escola [Escola Profissional Washington Luis] a constituir uma base solida do futuro radioso da terra brasileira (O MALHO, 29/12/1923 - grifos do original).

O registro gravado das entrevistas com diferentes sujeitos visa compor o acervo do Centro de Memória e, desta forma colaborar para a compreensão de aspectos da história da instituição. Se por um lado, compreendemos serem as informações que emergem das entrevistas importantes fontes no processo de análise e elucidação do passado; por outro entendemos que tais informações surgidas nas narrativas não podem ser tomadas como verdades sem a devida problematização, pois como afiança Alberti " [...] o equívoco está em considerar que a entrevista publicada já é História, e não apenas uma fonte que, como todas as fontes, necessita de interpretação e análise" (2014, p. 158).

\section{Por entre papeis e fios soltos: a história de uma escola de formação profissional}

A emergência de uma perspectiva de modernização da sociedade 
identificada com a industrialização fez surgir um discurso que além de se preocupar em integrar os indivíduos a essa lógica emergente, procurava criar a ênfase na adoção da técnica para a estruturação do trabalho produtivo. Para isso, era fundamental o desenvolvimento de uma educação de caráter nacional que priorizasse o ensino profissional, gratuito e obrigatório (CAMARA, 2013, p. 146).

A partir do final do século XIX, a educação e a escola foram perspectivadas como instâncias capazes de promover a regeneração e a prevenção social das crianças pobres, no entanto, foi a partir dos movimentos de renovação educacional que se organizaram na sociedade brasileira, nas décadas de 1920 e 1930, que o papel da escola se ampliou de maneira significativa. Assim, a escola deveria oferecer lições de cultura nacional, educando os costumes, os hábitos e instaurando um novo perfil de aluno, de professor e de espaço escolar associado aos referenciais de civilização e modernidade.

Ancorados na perspectiva de que era preciso instituir ações direcionadas a civilizar e progredir, à escola foi concebida como elemento capaz de despertar e desenvolver o sentido dos alunos quanto a importância da técnica, da racionalidade e do tempo como elementos associados a lógica do trabalho produtivo (CAMARA, 2013), mas também como "elemento central do processo de homogeneização cultural e de invenção de uma cidadania nacional" (NÓVOA,1998, p. 22).

Como defende Turazzi (1989, p. 81), trabalho, progresso e nacionalidade organizavam a máxima que se instituiu na sociedade dos anos de 1920 e 1930. A perspectiva do trabalho encontrava-se associada à ideia de prosperidade das indústrias e, portanto, da Pátria. Para isto, era preciso tornar o trabalho um valor positivo junto aos setores empobrecidos da sociedade. No caso do Rio de Janeiro, a autora defende que, até os anos de 1930 a estrutura industrial se caracterizava pelas oficinas e pequenas empresas de tecidos, mobiliários, metalurgia, construção etc., tendo "baixa concentração de capital operário e base técnica artesanal" (1989, p. 49). Nesta linha argumentativa, Manfredi (2002), afiança que:

Os novos empreendimentos industriais e o surgimento de grandes centros estimularam o incremento de serviços de infra-estrutura urbana de transportes e edificações. A modernização tecnológica (ainda que no nível de adaptação e de manutenção da tecnologia importada) inerente a esses novos setores da economia brasileira gerou novas necessidades de qualificação profissional e novas iniciativas, no campo da instrução básica e profissional popular (MANFREDI, 2002, p. 79). 
Deste modo, mediante a necessidade de crescimento industrial e com o imperativo de que era preciso formar para o trabalho profissional foi "criada, durante a presidência de Arthur Bernardes, nos moldes ultra-modernos" (Moção no 3661/2001), a Escola Profissional Washington Luís ${ }^{5}$, atual Escola Técnica Estadual Henrique Lage. Por iniciativa da Sociedade Técnica Fluminense a escola foi criada em Niterói, capital do Estado do Rio de Janeiro, em 23 de dezembro de 1923. À frente da proposta de criação da escola encontrava-se um grupo de engenheiros e professores da Escola Técnica Fluminense ${ }^{6}$, entre eles: Heitor Lira, Amerino Wanick, Everardo Backheuser, entre outros.

A criação da escola convergia com os ideais existentes à época no que concernia ao papel que deveria assumir à educação na formação e no "culto" ao trabalho junto às novas gerações. Desde sua criação, a escola contou com subvenção do governo do Estado e teve como seu primeiro diretor o professor Amerino Wanick, engenheiro formado pela Escola Politécnica do Rio de Janeiro, denominado como "gênio do Ensino Profissional" de acordo com a Moção (n 3661/2001). Três anos após a sua criação, a instituição foi incorporada ao patrimônio do governo do Estado do Rio de Janeiro, na gestão do Presidente do Estado Feliciano Sodré. A partir do decreto número 2.160 de 31 de janeiro de 1926, que regulamentou o ensino profissional do Estado do Rio de Janeiro, foram definidas as finalidades e à organização do ensino profissional. Quanto à Escola Profissional Washington Luís, esta manteve suas características iniciais: ênfase no ensino profissionalizante e predomínio de aulas práticas de ofícios, conforme o decreto:

Art. $1^{\circ}$ - O ensino profissional, de caráter essencialmente educativo, é gratuito para ambos os sexos e ministrado em estabelecimentos distintos, que funcionam sob o regime de externatos. Art. $2^{\circ}-$ Consiste o ensino profissional no lecionamento de artes e ofícios, paralelo à cultura física, intelectual e cívica dos alunos, e visa prepará-lo, de um modo geral, para a vida pratica e, especialmente, para o exercício do magistério em estabelecimentos congêneres e secções profissionais junto a institutos de ensino primário. Art. $3^{\circ}-\mathrm{O}$ ensino profissional se distingue em

\footnotetext{
${ }^{5}$ A criação da Escola Profissional com o nome do presidente do Estado de São Paulo, Washington Luís deveu-se a sua importância no cenário político da época. Nossa hipótese é que para além deste aspecto, as suas vinculações políticas e pessoais locais, bem como suas aspirações políticas à presidência da República podem nos ajudar a entender a homenagem realizada. Nascido em Macaé, Estado do Rio de Janeiro, Washington Luís construiu sua trajetória política em São Paulo, sendo alçado a Presidência da República, em 1926.

${ }^{6}$ Conforme Ignácio (2016), a Escola Técnica Fluminense era uma instituição educativa de ensino superior subvencionada pelo governo federal. Possuía os cursos de Construção Civil, Obras Públicas, Mecânica Eletricidade, Topografia e Química Industrial. Seu corpo docente era composto por engenheiros, a exemplo dos Drs. Heitor Lira, Amerino Wanick e Everardo Backheuser.
} 
masculino e feminino: o primeiro ministrado nas escolas "Visconde de Moraes" e "Washington Luís", na cidade de Niterói; o segundo, nas escolas "Nilo Peçanha" e "Aurelino Leal"- esta da cidade de Niterói e aquela de Campos (BRASIL, 1926).

A interferência da política nacional na instituição pode ser identificada, à princípio, pela substituição do nome da escola. Com a destituição do Presidente da República Washington Luís, em 1930, a escola assumiu a designação de Escola do Trabalho, a partir do Decreto $\mathrm{n}^{\circ} 2.541$ de 19 de janeiro de 1931. Com a deliberação de 1931, foi fundida à Escola Profissional Visconde de Moraes, passando a assumir a designação de Escola do Trabalho do Rio de Janeiro (BRASIL, 1931).

A nomenclatura de Escola do Trabalho do Rio de Janeiro permaneceu até 1941, quando pela deliberação de 20 de agosto deste ano, expedida pelo governador do Estado, Amaral Peixoto, a escola passou a se chamar Escola Profissional Henrique Lage. A justificativa para à homenagem ao industrial assentava-se na importância atribuída a ele e a sua família na criação de indústrias e estaleiros no Estado, mas também por iniciativas fillantrópicas $^{7}$ empreendidas, principalmente na cidade de Niterói.

Em sua disposição inicial a escola deveria oferecer atividades práticas, envolvendo ofícios em Madeira, Metal e Gráfica, sendo os cursos organizados em primário de adaptação, pré-profissional (a partir de 1929), profissional e noturno para o sexo masculino. Desde a sua criação em 1923 até a modificação do nome, a escola passou por duas reformas, a saber: uma em 1926, a partir do decreto 2.160 e, outra, em 1929, pelo decreto 2.380 , que alterou sua estrutura de ensino, faixa etária, tempo de escolarização, dias letivos, bem como os cursos oferecidos. Dentre as alterações propostas a partir de 1929, encontra-se a criação do curso Pré-Profissional, na qual os alunos provenientes do curso primário, eram obrigados a estudar por um ano para, então, prosseguir no curso profissional.

As atividades com desenho e trabalhos manuais em madeira, metal e artes gráficas foram enfatizados. Assim:

A Escola Profissional Washington Luís possuía como um de seus objetivos a formação integral do aluno, tendo como base sua formação profissional. Sendo capital do Estado, o município de Niterói, em grande expansão neste período, principalmente no setor industrial, precisava ater-se a necessidade

\footnotetext{
${ }^{7}$ O industrial em 1923, contribuiu com a doação de recursos para a criação, pelo governo de Estado e o Instituto de Proteção e Assistência à Infância de Niterói, como noticiou o jornal $O$ Fluminense de 05 de dezembro de 1923, da primeira Colônia Escolar de férias para crianças pobres do Estado do Rio de Janeiro. A Colônia foi criada na cidade de Mendes, no Estado do Rio de Janeiro.
} 
de qualificação de seus futuros cidadãos para trabalhar nestes novos setores de trabalho, a fim de auxiliar na renovação da cidade (IGNÁCIO, 2015, p. $3)$.

Importante destacar, que a presença do professor Amerino Wanick na direção da escola de 1923 a 1931, permitiu colocar em prática na instituição um projeto de ensino profissional que se encontrava articulado aos debates renovadores da educação nacional. Adepto da crença na educação, participou da criação da Associação Brasileira de Educação (ABE), em 1924, engajando-se no movimento de renovação da educação brasileira. Sob a batuta do escolanovismo empreendeu ações no âmbito do ensino, da assistência médica e alimentar, da higiene, das cooperativas que se materializaram na criação da distribuição do copo de leite e da sopa escolar, dos gabinetes médico e dentário, da biblioteca escolar, da caixa escolar, do escotismo, da cooperativa colegial, das excursões escolares da prática da educação física.

Exemplar nesta direção foi a matéria publicada no jornal Diário Carioca, do dia 18 de novembro de 1928, tendo por título "Como será comemorado o dia da bandeira”, em que faz alusão às comemorações na Escola. A matéria apresentava às atividades cívicas, com destaque para o hasteamento da bandeira, o hino nacional e o discurso do professor de moral e cívica, professor João Rebello Pinheiro; as atividades esportivas com desfile dos alunos e campeonatos de vôlei, pirâmide, corrida; as atividades literárias, na qual o diretor Amerino Wanick discursou e foram apresentadas peças teatrais, contos e música.

Nesta perspectiva, a escola para além de ministrar o conhecimento e a prática de um ofício, deveria contribuir para dilatar o horizonte social das crianças, apresentando como uma de suas atividades a realização, ao final do ano letivo, de exposições dos produtos confeccionados nas oficinas da escola. Nas exposições ocorriam à venda dos produtos aos visitantes que, a exemplo das escolas profissionais do Distrito Federal, eram produzidos pelos alunos nas oficinas. Uma parte do dinheiro da venda era revertida para a caixa escolar e, a outra, aos alunos como forma de remunerá-los.

Aos alunos que tenham tomado parte na execução dos serviços industriais, a que se refere o $\$ 2^{\circ}$, será creditada uma remuneração, segundo a avaliação do respectivo trabalho, feita pelo mestre da secção, com aprovação do Diretorremuneração essa que será entregue ao menor em efeitos adquiridos pelo Diretor para satisfação das mais prementes necessidades do discente (BRASIL, 1929, p. 50). 
Essa estratégia foi adotada visando colaborar para à permanência das crianças nas escolas, uma vez que o seu trabalho era, em muitos casos, requerido pelas famílias que necessitavam lançar mão a fim de complementar à renda familiar. Como afiança Araújo (1995, p. 49) em geral, nas famílias pobres todos - pais, mãe e os filhos, necessitavam trabalhar, devido a renda familiar ser "baixa e irregular". Devido as demandas por sobrevivência era comum encontrar crianças pedindo esmolas pelas ruas ou desenvolvendo atividades de engraxate e vendedores ambulantes o que as colocava em contato constante com riscos de contaminação moral e física. ${ }^{8}$

Imagem I: Galpão de exposição dos produtos confeccionados nas oficinas.

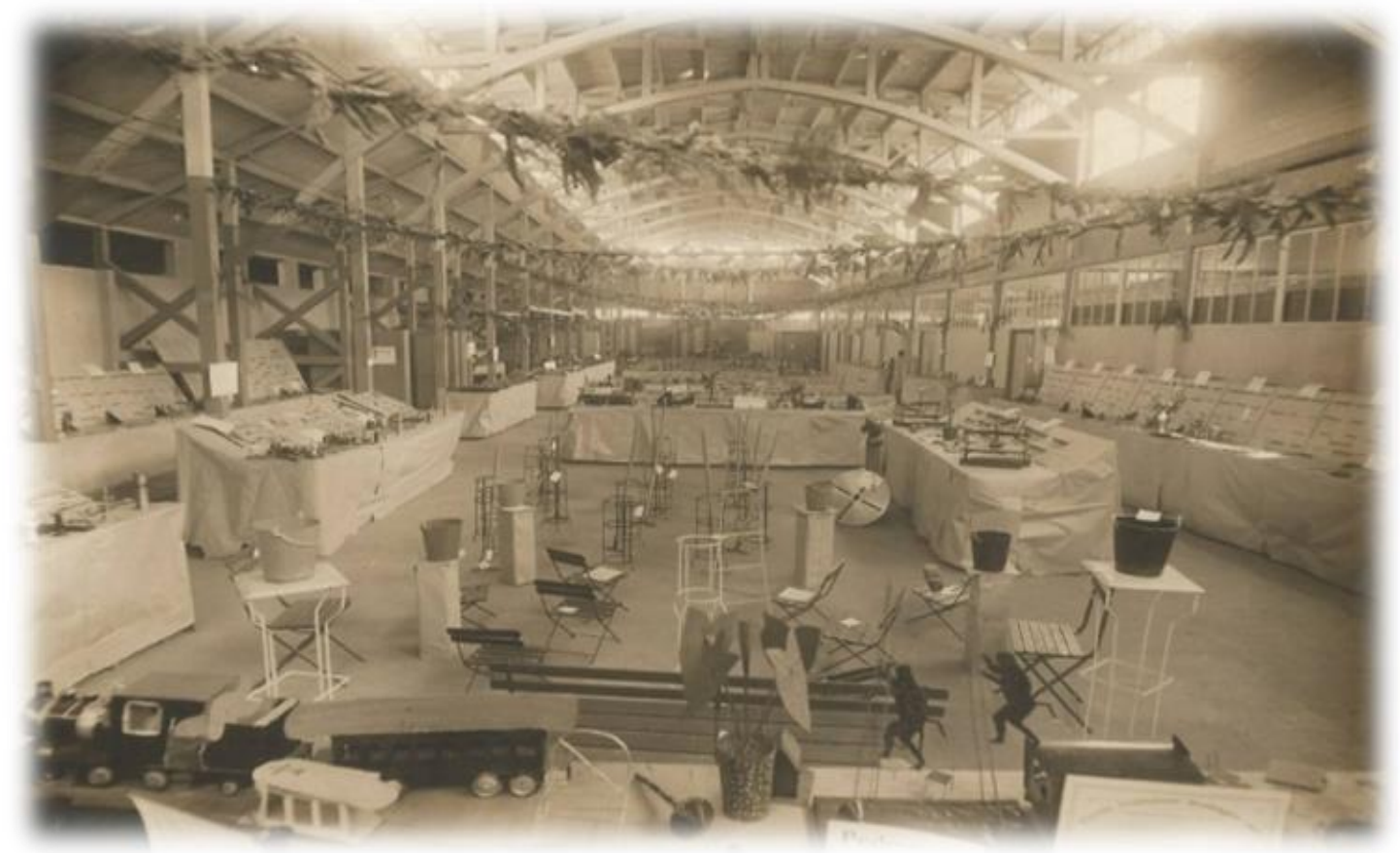

Fonte: Acervo Centro de Memória da Escola Henrique Lage, 1927.

Outro aspecto que mereceu destaque foi a adoção de práticas destinadas a desenvolver hábitos de higiene e de saúde junto aos alunos. Lema dos médicos higienistas, a prerrogativa de que era preciso investir na escola como espaço de constituição de medidas educativas e práticas assistenciais, organizou a criação do Gabinete Dentário Escolar e a distribuição do prato de sopa, bem como a realização de preleções de orientação aos professores e alunos.

\footnotetext{
${ }^{8}$ Embora a idade mínima de oito anos para a admissão de crianças no trabalho em fábricas tenha sido definida por lei de 1894, era possível ainda na década de 1920 encontrar crianças de todas as idades trabalhando. O Código Sanitário de 1894, regulamentou o trabalho infantil, proibindo o emprego de menores de 12 anos nas fábricas. Somente em 1927, com o Código de Menores ficou proibido o trabalho de menores de 14 anos. Cf Araújo, 1995; Camara, 2010.
} 
Desta forma, a partir do Decreto $\mathrm{n}^{\circ} 2.380$ de 1929, ficou estabelecido que haveria o serviço médico e dentário a ser realizado por um corpo de profissionais indicados pelo Diretor da Saúde Pública ou, em alguns casos poderia ser custeado pela caixa escolar desonerando o Estado de sua responsabilidade com o atendimento dos escolares (BRASIL, 1929, p. 42).

Imagem II: Gabinete Dentário da Escola Profissional Washington Luis.

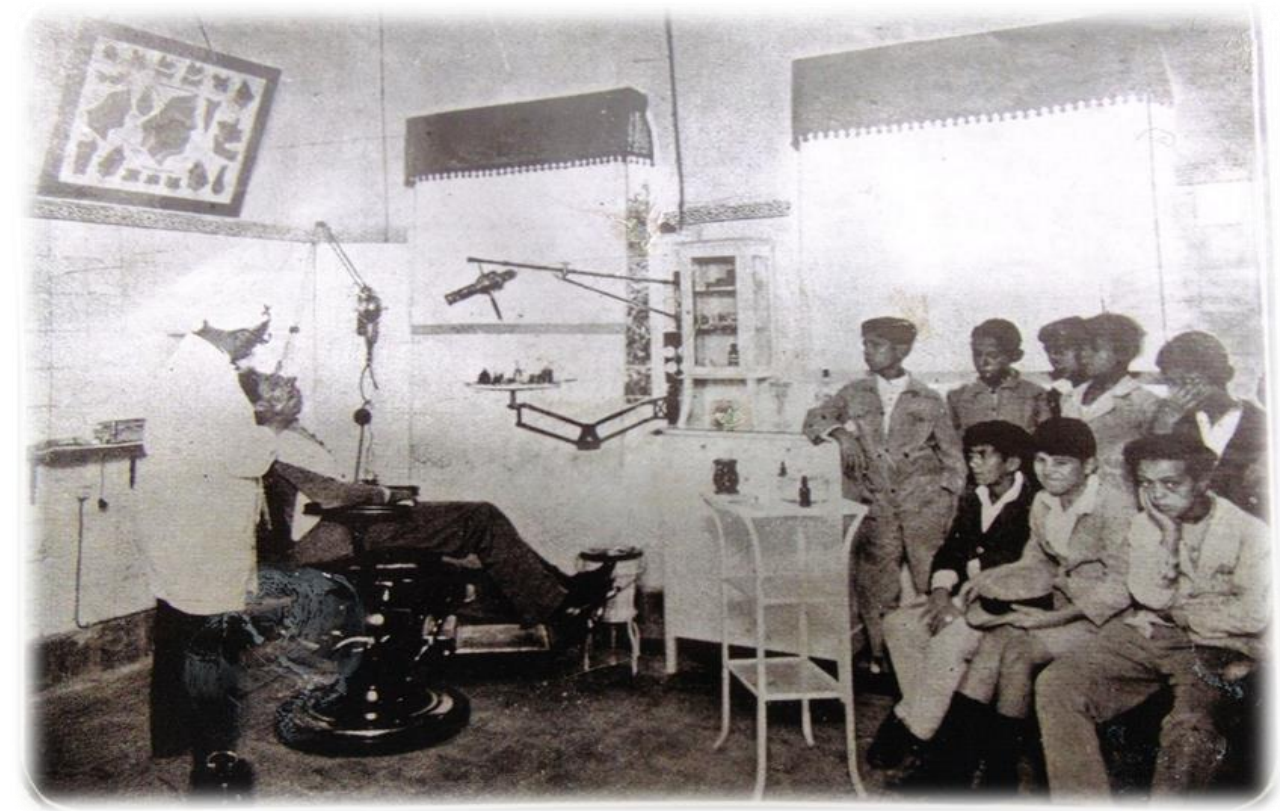

Fonte: Acervo do Centro de Memória Henrique Lage, 1929.

Objetivava-se ampliar o poder de alcance da escola para além do ler, escrever e contar. Visavam, assim, estabelecer a formação de valores morais e higiênicos associados ao ideal de modernização do País. Nesta direção, Vidal afirma que a ampliação da escolarização as "camadas menos favorecidas" significou o afastamento das crianças do trabalho. Para a autora, estabelecia-se uma luta que expunha "representações concorrentes" em torno da escola e de sua função social, assim:

[...] de um lado, a escolarização larga, que pressupunha a formação de hábitos e valores para além da instrução nos saberes básicos (uma escolarização do social); de outro, a escolarização curta, instrumental, visando o fornecimento dos conhecimentos necessários à sobrevivência em sociedade cada vez mais marcada pelo universo da escrita, cujos signos nem sempre eram partilhados pelas classes menos favorecidas (VIDAL, 2004, p. 8-9). 
A partir da adoção de práticas de higiene e hábitos saudáveis, bem como dos conhecimentos instituídos em seus programas, a Escola Henrique Lage instituiu a escolarização mediada pela imposição de hábitos higiênicos e a instrumentalização de saberes específicos associados ao mundo do trabalho, mas também ao universo da escrita às crianças. Para isso, convocaram os professores e auxiliares como elementos essenciais à transformação da escola e dos escolares.

Nesta direção, analisando os documentos relativos aos alunos ${ }^{9}$, é possível afirmar que esses advinham das classes menos favorecidas e, em grande parte, não conseguiam concluir o ciclo de escolaridade oferecido pela escola, evadindo após os primeiros anos do curso. Aspecto possível de ser observado a partir da análise do número de matrículas realizadas na instituição.

\begin{tabular}{|c|c|c|c|c|c|c|}
\hline \multicolumn{7}{|c|}{ Quantitativo do Número de Matrículas no Curso Profissional (1924-1930) } \\
\hline Ano & $\begin{array}{l}\text { Pré- } \\
\text { profissional }\end{array}$ & $\begin{array}{l}1^{\circ} \text { ano } \\
\text { Profissional }\end{array}$ & $2^{\circ}$ ano & $3^{\circ}$ ano & $4^{\circ}$ ano & Total \\
\hline 1924 & ------------- & ------------------. & |----- & ---------- & ---------- & $\begin{array}{l}58 \text { alunos } \\
\text { matriculados }\end{array}$ \\
\hline 1925 & ------------- & -------------- & ----- & ---------- & --------- & $\begin{array}{l}\text { Não } \\
\text { localizado }\end{array}$ \\
\hline 1926 & ------------- & 37 & 09 & ---------- & --------- & $\begin{array}{l}46 \text { alunos } \\
\text { matriculados }\end{array}$ \\
\hline 1927 & ------------- & 55 & 13 & 06 & ---------- & $\begin{array}{l}74 \text { alunos } \\
\text { matriculados }\end{array}$ \\
\hline 1928 & ------------ & 84 & 31 & 07 & 05 & $\begin{array}{l}\text { 127alunos } \\
\text { matriculados }\end{array}$ \\
\hline 1929 & 48 & 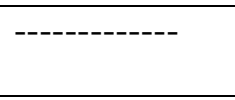 & ------ & $\begin{array}{c}----- \\
\end{array}$ & ------ & $\begin{array}{l}48 \text { alunos } \\
\text { matriculados }\end{array}$ \\
\hline 1930 & 52 & 59 & 43 & 13 & 07 & $\begin{array}{l}174 \text { alunos } \\
\text { matriculados }\end{array}$ \\
\hline
\end{tabular}

Quadro elaborado por nós a partir dos Relatórios dos Presidentes dos Estados Brasileiros.

Os dados iniciais, constituídos a partir da análise das fontes, nos permitem identificar os aspectos que concorreram para o expressivo número de evasão e, por outro para o ínfimo

\footnotetext{
${ }^{9}$ Estão sendo organizados dossiês de alunos compostos por documentos variados dos alunos, como requerimento de matrícula, certidão de nascimento, atestado de vacinação, declaração de escolaridade, declaração de pobreza e outros.

10 Número de matriculados obtidos pelos Relatórios dos Presidentes dos Estados Brasileiros, pelo então presidente do Estado do Rio de Janeiro, Feliciano Pires de Abreu Sodré, em 01 de agosto de 1924, na qual apenas forneceu o número total de matriculados, não especificando o ano cursado. Disponível em: http://memoria.bn.br/DocReader/DocReader.aspx?bib=720488\&pesq=Escola\%20Washington\%20Luis. Acessado em outubro de 2015.
} 
número de alunos que concluíam o curso, como demonstrado, no quadro, pelo número de concluintes no $4^{\circ}$ ano, ou seja 05, em 1929 e 07, em 1930. A situação de pobreza e a emergência do trabalho das crianças pelas famílias podem ter-se constituído em vetores importantes na compreensão dos "dados" que emergem dos documentos, no entanto consideramos que os aspectos relacionados a importância atribuída à escolarização, bem como a organização da escola devem ser considerados para efeito de analise.

Desta maneira, compreendemos que a organização curricular da Escola contribuiu para o reduzido número de concluintes do curso, uma vez que funcionava a partir do sistema rotativo, no qual o aluno, nos dois primeiros anos de escolarização, tomava contato com todos os ofícios oferecidos pela escola e, nos dois últimos anos realizava a especialização em um ofício que apresentasse maior vocação ${ }^{11}$. Interessante observarmos que a ideia da vocação e da aptidão aparecem como premissas que deveriam orientar à escolha pelo aluno por um ofício, no entanto consideramos que esses critérios são determinados, em grande parte, pela ação dos mestres e da escola. Nesta direção, importa observar que o problema da evasão da escola e, em especial das escolas profissionais foi uma questão identificada também no Distrito Federal, onde o Diretor da Instrução Pública, Antonio Carneiro Leão indicava ser a evasão um dos grandes problemas do ensino. A fim de minimizar a situação instituiu, no período da Reforma Educacional que dirigiu (19221924), um sistema de pagamento dos alunos pelo trabalho realizado nas oficinas, a fim de que esse não evadisse sem concluir o curso profissional. Em geral, as crianças após os primeiros anos no sistema rotativo, deixavam a escola e iam trabalhar em alguma oficina ou fabrica da região. Mediante a isto,

É como ser de outra forma se é tão raro chegar algum rapaz ao $4^{\circ}$ ano da escola profissional masculina? No final do $2^{\circ}$ e quando muito do $3^{\circ}$ ano estão deixando os moços as escolas para ir frequentar oficina particular, ou fabrica, com o fim de ganhar o que comer, embora vegetem, depois, incapaz de estimulo e de progresso a vida toda! [...]. A causa, nesse particular, estou certo, é a penúria econômica dos pais. Logo que os filhos começam a fazer qualquer coisa nos retiram da escola e colocam numa oficina qualquer, como aprendizes. O único meio, pois, de evitar, o lamentável êxodo das escolas profissionais masculinas será estabelecer uma diária para o aluno a partir do $2^{\circ}$ ano e dar-lhe uma refeição diariamente (CARNEIRO LEÃO, 1926, p. 189-190).

\footnotetext{
${ }^{11}$ A vocação era indicada, em geral pelos mestres que avaliavam o desempenho dos alunos.
} 
Neste sentido, a evasão dos cursos são vestígios importantes que merecem maior investigação quanto as suas causas. Com faixa etária de 11 a 16 anos e em grande parte moradores de Niterói, os alunos tinham seu ingresso, em muitos casos, no curso primário de adaptação, por exame de admissão ou com certificação da $3^{\circ}$ ou $4^{\circ}$ série do ensino primário de outras escolas públicas e ou grupos escolares, conforme estabelecido como requisito de entrada no curso profissional pelo Regulamento do ensino profissional do Estado do Rio de Janeiro (DECRETOS, no 2.160 de 1926 e no 2.380 de 1929). Com intuito de oferecer instrução técnica necessária pretendeu-se realizar uma formação integral do aluno, na qual, em seu artigo segundo afirmava que consistia ao ensino profissional lecionar "artes e ofícios, paralelo à cultura física, intelectual e cívica dos alunos, e visa prepará-los, de um modo geral, para a vida prática e, especialmente, para o exercício do magistério em estabelecimentos congêneres e seções profissionais junto a institutos de ensino primário" (BRASIL, 1926). De tal modo, a escola deveria organizar-se em estreita relação com as demandas da região aonde estava localizada. Nesta direção, o decreto $\mathrm{n}^{\circ}$ 2.570 de 17 de abril de 1931 enfatizava que a educação profissional:

[...] tem por objetivo fundamental a execução de um plano de educação integral, que assegure o livre desenvolvimento da personalidade do aluno, bem como que proporcione, finalmente aos jovens educandos uma preparação profissional e técnica, subordinada a uma instrução de caráter essencialmente prático, que habilite o homem para a vida, (Decreto $\mathrm{n}^{\circ} 2.570$ de 17 de abril de 1931).

Portanto, desde sua criação, a Escola Profissional Washington Luis veio se constituindo como um importante espaço de formação profissional na região. As fotografias encontradas, os objetos, bem como os documentos textuais têm possibilitado evidenciar que a prerrogativa de se promover a educação profissional não se assentava apenas no ensino prático, envolvia proposições que se organizavam nos fazeres ordinários da escola ampliando o seu poder de alcance para além de uma perspectiva econômica formal de formação de mão de obra para o trabalho, indo ao encontro da formação cívica, moral, cultural e higiênica das crianças.

\section{Por uma tessitura possível: algumas questões iniciais}

O trabalho realizado a partir da parceria institucional da universidade com a escola na 
efetivação da pesquisa tem permitido produzir interpretações acerca dos aspectos que mobilizaram as ações e os fazeres na escola no âmbito da formação para o trabalho, potencializando, ainda, pensarmos sobre a importância dos seus acervos na constituição de outras interpretações que levassem em conta as dinâmicas cotidianas envolvendo os sujeitos na escola, assim como o próprio contexto social, político e econômico. Desta forma, a tessitura dessa trama tem permitido colaborar para a construção de uma história da instituição que se realiza a partir de documentos produzidos pela escola em suas práticas ordinárias. De certo que o manuseio com os documentos da instituição, bem como a significação de objetos usados na escola têm permitido promover um movimento reflexivo na instituição acerca de sua história, mas também da necessidade de se pensar acerca das políticas de preservação e de descarte documental. Assim, a efetivação do processo de identificação, sistematização, divulgação e análise dos objetos e documentos que compõe o acervo, em questão, demanda um empenho permanente e conjunto da universidade e da escola em torno da importância da história da educação que emerge das análises que considerem estes diferentes suportes documentais na sua construção e escrituração.

\section{Referências:}

ALBERTI, Verena. Histórias dentro da História. PINSKY, Carla (org.) Fontes históricas. São Paulo: Contexto, 2014.

. Ouvir contar: textos em história oral. Rio de Janeiro: Editora FGV, 2004.

BACELLAR, Carlos. Uso e mau uso dos arquivos. PINSKY, Carla (org.) Fontes históricas. São Paulo: Contexto, 2014.

ARAÚJO, Roma Maria B. A Vocação do Prazer: a cidade e a família no Rio de Janeiro republicano. Rio de Janeiro: Rocco, 1995.

BELlotTO, H. L. Arquivos permanentes: tratamento documental. São Paulo: T. A. Queiroz, 1991.

BONATO, Nailda Marinho da Costa. Os arquivos escolares como fonte para a história da educação. Revista Brasileira de História da Educação, Maringá, Pr, v. 2, n. 5, p.193-220, 2005. Disponível em: <http://www.rbhe.sbhe.org.br/index.php/rbhe/article/view/175/183>. Acesso em: 18 nov. 2015.

BRASIL. Decreto $\mathbf{n}^{\mathbf{0}} \mathbf{2 . 1 6 0}$ de 31 de janeiro de 1926. Regulamento do Ensino Profissional do estado do Rio de Janeiro. 
. Decreto $\mathbf{n}^{\circ} \mathbf{2 . 3 8 0}$ de 14 de janeiro de 1929. Regulamento do Ensino Profissional do estado do Rio de Janeiro.

. Decreto $\mathbf{n}^{0} 2.570$ de 17 de abril de 1931. Regulamento do Ensino Profissional do estado do Rio de Janeiro.

- Monção $\quad \mathbf{n}^{\circ}$ 3661/2001. Disponível em: http://alerjln1.alerj.rj.gov.br/scpro99.nsf/fd0d0b8fc385d589832567040006b056/0d5ad29b26f 2c92d03256a2a006e5a64?OpenDocument. Acessado em: 24/06/2013.

CAMARA, Sônia. Reiventando a Escola. O Ensino Profissional Feminino na Reforma Fernando de Azevedo de 1927 a 1930. Rio de Janeiro: Quartet, 2013.

CAIXETA, Maria Cristina Diniz; CUNHA, Maria Aparecida Carvalhais. Gestão documental e resgate da memória na Justiça do Trabalho: preservação documental é direito do cidadão e dever do Estado. Cadernos de História, Belo Horizonte, v. 14, n. 20, $1^{\circ}$ sem. 2013. p. 32-46. Disponível em: <http://200.229.32.55/index.php/cadernoshistoria/article/viewFile/P.22378871.2013v14n20p32/7033>. Acesso em: 26 fev. 2016.

CARVALHO, Marta. Reformas da Instrução Pública. LOPES, E. Marta T.; FARIA FILHO, Luciano M.; VEIGA, Cynthia G. (orgs.) 500 anos de Educação no Brasil. Belo Horizonte: Autêntica, 2000.

FAETEC - Fundação de Apoio a Escola Técnica. Disponível em: $<$ http://www.faetec.rj.gov.br/index.php/institucional/programas-e-projetos/centro-de memoria>. Acesso em 07 dez. 2015.

IGNÁCIO, Sâmela Cristinne F. de Carvalho. Rastros e indícios do movimento escolanovista no período de 1927 a 1930 na escola profissional Washington Luis: a reforma Fernando de Azevedo no Distrito Federal. In: CONGRESSO BRASILEIRO DE HISTÓRIA DA EDUCAÇÃO, 2015, Maringá. Anais [Maringá]: Universidade Estadual de Maringá, 2015. Disponível

em: <http://8cbhe.com.br/media/doc/ef3573423e351a665fba73acc8f42f5f.pdf>. Acesso em: 12 nov. 2015.

IGNÁCIO, Sâmela Cristinne F. de Carvalho. A (Re) Construção Histórica da Escola Profissional Washington Luis (1923-1931). Dissertação de Mestrado em EducaçãoUniversidade Federal do Estado do Rio de Janeiro (Unirio), 2016.

LE GOFF, Jacques. História e Memória. São Paulo: Editora da Unicamp, 1990.

MANFREDI, Silvia Maria. Educação profissional no Brasil. São Paulo: Cortez, 2002.

NÓVOA, Antonio. Relação escola - sociedade: "novas respostas para um velho problema". SERBINO, Raquel V.; RIBEIRO, Ricardo [et.al.]. Formação de Professores. São Paulo: Editora da UNESP,1998.

O FLUMINENSE, 05/12/1923. 
O MALHO, 29/12/1923.

O JORNAL, de 17/06/1928.

POLACK, Michel. Memória e Identidade Social. Revista de Estudos Históricos. Rio de Janeiro: Associação de Pesquisa e Documentação Histórica, v. 5 n. 10, 1992, (p. 200-212).

PROGRAMMA, Para os Jardins de Infância e Escolas Primárias. Rio de Janeiro: Prefeitura do Distrito Federal, 1929.

TURAZZI, Maria Inez. A euforia do progresso e a imposição da ordem: a engenharia, a indústria e a organização do trabalho na virada do século XIX ao XX. Rio de Janeiro: COPPE; São Paulo, Marco Zero, 1989.

VIDAL, Diana Gonçalves. O fracasso das reformas educacionais: um diagnóstico sob suspeita. In: V Congresso Luso-Brasileiro de História da Educação: igreja, Estado, sociedade civil- instâncias promotoras do ensino. Mesa-redonda. Évora, Portugal, 2004, p.8-9, Mimeo. 